\title{
ESTADO, MERCADO E EDUCAÇÃO SUPERIOR NO BRASIL: UM MODELO ANAL
}

\author{
Alfredo Macedo Gomes
}

\begin{abstract}
RESUMO: O artigo apresenta modelo explicativo que discute o potencial de formação dos processos de coordenação e controle disputados pelo Estado e setores constituintes da educação superior no Brasil (os setores federal e o privado). A tese central é a de que a reestruturação do campo de ensino superior proposta pelos govemos Femando Henrique Cardoso redefine o potencial e os mecanismos de coordenação e controle das principais forças sociopolíticas e institucionais que constituem e/ou agem fortemente sobre as atividades e os destinos da educação supenior no Brasil. À luz da análise empreendida, conclui-se propondo o modelo da "Metáfora da Flutuação", que representa uma revisão do "Triângulo da Coordenação" de Clark (1983), e destaca-se que a política de reforma oficial implicou o fortalecimento do potencial de coordenação e regulação do Estado, ao mesmo tempo que aumentou o poder de coordenação do mercado e diminui a força coordenadora da comunidade acadêmica.
\end{abstract}

Palavras-chave: Política educacional. Educação supenior. Coordenação e controle. Setores público e privado.

\section{STATE, MARKET AND HIGHER EDUCATION IN BRAZIL: \\ AN ANALYTICAL MODEL}

\begin{abstract}
This paper presents an explanatory model that discusses the potential of the coordination and control processes that became a bone of contention between the Federal State and public (Federal) and private sectors of higher education, in Brazil. Its main thesis is that the restructuring of higher education advocated by the two successive Fernando Henrique Cardoso's administrations (1995-2002) redefined both the potential and mechanisms of co-
\end{abstract}

Professor-Doutor do Departamento de Fundamentos Sócio-Filosóficos da Educação e do Programa de Pós-Graduação em Educação da Universidade Federal de Pernambuco (UFPE). E-mail: alf1964@terra.com.br 
ordination and control of the main sociopolitical and institutional forces that constitute, and/or strongly impact on, the activities and destiny of higher education. In light of this analysis, it concludes proposing the Fluctuation Metaphor Model, which is a revision of Clark's Triangle of Coordination (1983), and highlighting that the higher education reform strengthened both the coordination and regulation potential of the State and the coordination power of the market while it weakened the coordinating strength of the academic community.

Key words: Education policy. Higher education. Coordination and control. Public and private sectors.

\section{Introdução}

\section{A} presenta-se, no presente artigo, uma proposta analítica que visa a contribuir para o entendimento da dinâmica de poder que caracteriza o desenvolvimento contemporâneo do Sistema ${ }^{1}$ de Educação Superior Brasileiro (SESB). Objetiva-se, especificamente, delinear um modelo explicativo que explicite a potência de formação e manutenção dos processos de coordenação e controle disputados pelo Estado e pelos setores constituintes da educação superior no Brasil, particularmente os setores público-federal e o privado. A tese defendida neste trabalho é a de que a reestruturação do campo da educação superior proposta pelos govemos Femando Henrique Cardoso, na esteira da reforma do Estado brasileiro, buscou, sobretudo, redefinir a potência, os instrumentos e mecanismos de coordenação e controle das principais forças sociopolíticas e institucionais que constituem e/ou agem fortemente sobre as atividades e os destinos da educação superior no Brasil (o Estado, a academia, o mercado e as representantes das instituições de ensino superior). A política de reforma oficial é no sentido de equipar e fortalecer o potencial de coordenação, controle e regulação do Estado (ou govemamental) e estabelecer mecanismos para aumentar o poder de coordenação do mercado, objetivando diminuir, nesse movimento, a força coordenadora da comunidade acadêmica.

O modelo proposto representa uma revisão do "Triângulo da Coordenação" formulado por Burton Clark (1983), o qual vem sendo utilizado como instrumento de análise comparativa do comportamento dos sistemas nacionais de educação superior (Goedegebuure et al., 1994) ante o Estado e o mercado.

Inicia-se, pois, com a apresentação e discussão do modelo do "Triângulo da Coordenação" de Clark (1983). Logo em seguida, já 
realizando trabalho empírico-analítico, explicitam-se as novas linhas estruturais do sistema de educação supenior brasileiro e passa-se, depois, à análise de um conjunto de instrumentos e mecanismos de coordenação e controle associados às quatro formas de coordenação (Estado, Mercado, Academia e Institucional) dos setores público-federal e privado. A seção seguinte dedica-se à análise da dinâmica de coordenação e controle, a partir da proposição de um modelo denominado a "Metáfora da Flutuação". Os setores federal e privado são posicionados ante esse modelo, o qual representa um desenvolvimento do quadro de potencial de coordenação trabalhado na seção anterior.

\section{O Triângulo da Coordenação de Clark}

O Triângulo da Coordenação consiste de três (tipos ideais) sistemas: o Estado, o mercado e a academia. Cada sistema tem sua própria dinâmica, caractenísticas e funções. Das interações e trocas entre eles, um específico tipo de coordenação do sistema de ensino superior pode serinferido.

Figura 1

(Triângulo da Coordenação de Clark - 1983)

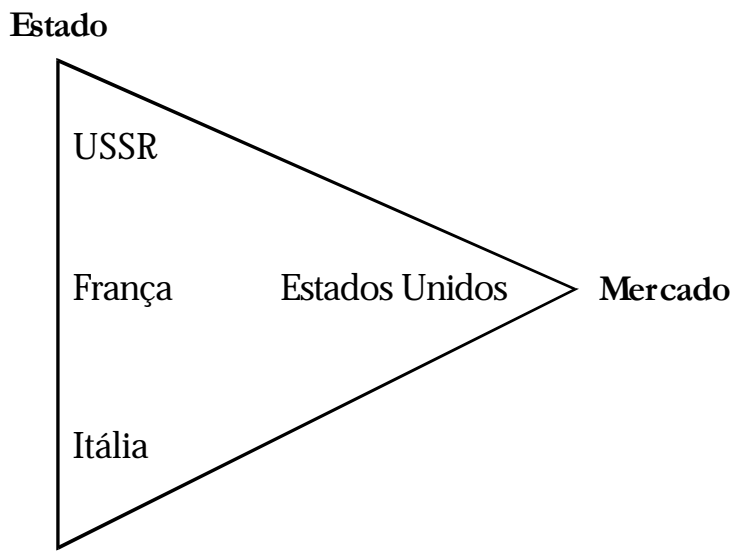

\section{Oligarquia Acadêmica}

A coordenação estatal ou do Estado varia de coordenação burocrática a coordenação política, dependendo das características predo- 
minantes que dirigem o sistema de educação superior. Quando o tipo burocrático é predominante, Clark (1983, p. 146-50) observa expansões múltiplas em "estratos", jurisdição, pessoal, especialização administrativa e leis.

Estratos puxam a superestrutura administrativa verticalmente; a expansão junisdicional engessa-a horizontalmente; o crescimento do quadro de pessoal preenche-a com mais pessoas; a especialização administrativa com mais experts; e a expansão das nomas garante que estrutura nivelada e melhor posicionada terá um comespondente massivo como de regulamentos. (Clark, 1983, p. 150)

O tipo burocrático de coordenação aumenta os "níveis de coordenação formal, govemamental ou quase govemamental", no qual a dinâmica de mudança é centrada em leis e regulamentos. Essa dinâmica de mudança (ou estagnação) é uma característica fortemente presente no caso brasileiro (Gomes, 2000a). Porém, contrariamente à onda de expansão das normas que foi pensada para dar "consistência à ação das pessoas dentro do sistema" de ensino superior, o que tem sido observado, a partir de meados dos anos de 1980, é a preocupação dos governos no sentido de "não aprovar legislação específica, mas leis gerais que cobrem mais atividades, porém com menos detalhes" (Clark, 1983, p. 150). ${ }^{2}$ Isso coincide com a disseminação da fé ideológica no mercado como um instrumento de coordenação e regulação.

Clark (idem, p. 153) observa que a autoridade política é uma "forma legítima de poder no e em tomo dos sistemas de educação superior, servindo como uma altemativa básica às formas burocrática e profissional (acadêmica)". Quando a coordenação política é dominante, os processos de tomada de decisão são muito mais abertos à influência, seja em períodos eleitorais, ou no cotidiano dos parlamentos, ministérios, conselhos etc. A educação superior toma-se então uma "prioridade" política. Com o advento da massificação dos sistemas de ensino superior, muito mais pessoas passam a prestar atenção ao fato de como políticos e legisladores se posicionam com relação às questões do ensino superior. Outra característica da coordenação política é o envolvimento político dos govemos, legisladores e partidos políticos de forma regular nas questões específicas da educação superior. Como conseqüência, a educação superior está sujeita à "barganha política e à negociação" (idem, p. 152). Em alguns sistemas de ensino superior, a representação dos interesses intemos (da academia) tem se convertido em importante parte do processo de coordenação política. 
Neste sentido, Clark (idem, p. 154) enfatiza que, em certos sistemas, "os métodos de representação têm se movido do informal para o formal, from the soft to the hard". Aqui, como sabemos, três grupos participam: os professores (acadêmicos), os funcionários técnico-administrativos e os estudantes. Contudo, Clark indica que "representação contínua sobre temas complicados (...) toma-se matéria para uma pequena elite e não para o envolvimento das massas" (idem, p. 157).

Comparando as formas de coordenação burocrática e política, Clark (idem, p. 157) argumenta que "processos burocráticos são mais imediatos, focalizados e duráveis. Educação superior não sobe e desce como uma questão importante para um ministério ou departamento ou conselho ou comitê de educação superior. É seu business, todo o tempo e o tempo todo".

Daí resulta que coordenação estatal é uma "combinação" da autoridade burocrática e política. Apenas analisando um contexto particular e objetivo, e as relações de poder que caracterizam o processo de tomada de decisão no que conceme às políticas para o ensino superior, é possível chegar à conclusão acenca de que faceta da coordenação estatal é dominante. Dado que a educação superior é o business de um ministério ou secretaria, e que as pessoas envolvidas neles estão engajadas o tempo todo em nível crescente de especialização com os problemas e as dificuldades da área, pode-se então supor que a forma burocrática - na visão de Clark - parece exercer de forma regular o poder coordenador mais que a forma política. Contudo, uma dificuldade particular emerge desse modelo "bipolar" de autoridade estatal, isto é, como separar o político do burocrático, se se entende que burocracia é organizada para a realização de objetivos políticos de um determinado govemo.

A autoridade acadêmica ou profissional é a segunda força presente no processo de coordenação dos sistemas de ensino superior. De acordo com Clark (1983, p. 158-161), o poder da autoridade acadêmica baseia-se no conhecimento (expertise) que caracteriza a vida acadêmica. Métodos para aumentar a autoridade acadêmica ocorrem por intermédio de uma tripla expansão: a expansão do conhecimento, dos colegiados, plenosou conselhos departamentais e centraise do interesse da faculdade. A autoridade do conhecimento decorre do "conhecimento esotérico dos professores", e é o departamento "a unidade de autoridade para uma dada disciplina ou campo profissional". Acrescenta-se que os colegiados têm se tomado parte da fisionomia nacional da grande maioria dos sistemas de educação superior. Em determinado ní- 
vel, existem aqueles ligados às atividades de suporte/controle do financiamento de pesquisa, nos quais os "pares" colocam em prática seus conhecimentos e seus poderes em comissões, comitês ou conselhos nacionais, regionais ou locais. Em outro nível, localizam-se aquelas organizações formadas por associações representativas dos diversos setores da educação superior, muitas das quais com funcionários em tempo integral e "lobistas" políticos. Em um terceiro nível, encontramse associações acadêmicas, sindicatos e outras instituições representativas dos segmentos universitánios.

Clark (idem, p. 160-161) observa que a "coordenação profissional é menos óbvia que as formas burocrática e política, mas ela é operativa e freqüentemente potente".

O mercado é a terceira força do Triângulo da Coordenação de Clark. Ao passo que o papel coordenativo do Estado decorre de leis e regulamentos (a forma burocrática) e do poder legítimo (a forma política), e ao passo que o poder acadêmico se baseia na expertise e no conhecimento, a coordenação do mercado é baseada em um princípio flexível. Clark selecionou o conceito de escolha social (social choice) para indicar a fundação dessa forma radicalmente diferente de coordenação (idem, p. 161). Para ele, escolha social

(...) é produto acidental das ações de dois ou mais atores (...) que não têm as mesmas intencõese que fazem suas escolhas competitivamente ou sem consideração de um com relação ao outro (...) cada atorprocura realizar seus próprios fins; 0 agregado de todas as ações - a situação produzida portodas as ações conjuntas - constitui um resultado para o grupo, mas é um resultado que ninguém planejou como uma "solução" para um "problema". Éuma resultante muito mais que uma solução. (Banfield apud Clark, 1983, p. 137)

Este conceito fundamenta a ação dos agentes no mercado. A coordenação do mercado representa, no modelo de Clark, a antítese do Estado (idem, p. 138), e "trabalha sem o benefício de uma superestrutura: são trocas desregulamentadas que conectam pessoas e situações" (idem, p. 162). "Troca", Clark (idem, p. 138) advoga, "é a forma básica de interação que se levanta em contraste com o comando autoritánio; ele pode servisto como um método para organizar a cooperação entre as pessoas". Hayek (1997, p. 27) o denominaria de "competição". Eu exploro logo abaixo as significações dessa antítese, argumentando que govemo ou Estado está grandemente envolvido no processo de troca, e que o mercado no ensino supenior tem, ao contránio do que Clark argumenta, se beneficiado de uma superestrutura. 
Como um tipo ideal de coordenação, o mercado é dividido em três: mercado consumidor, mercado de trabalho e mercado institucional (Clark, 1983, p. 162). O mercado consumidor desempenha um papel significativo nas missões e atividades das instituições de ensino superior. "A caracteństica central é o poder do consumidor", e a moeda, o número de alunos matriculados. Em alguns sistemas, os governos usam regularmente tais mercados para oferecer "bolsas de estudos e outras formas de ajuda financeira para os estudantes" (idem, ibid.), que são livres para escolher que cursos ou em que instituições eles querem estudar. Em contrapartida, instituições de ensino superior, quando a estrutura do sistema permite, competem por estudantes. "A economia das matrículas" (idem, p. 163) passa a ser central para a sobrevivência institucional tanto em instituições públicas como nas particulares. $\mathrm{O}$ crescimento da forma de coordenação do mercado por meio do poder do consumidoré parcialmente reconhecido como uma resposta aos procedimentos burocráticos do planejamento central, por intermédio dos quais "atores govemamentais e acadêmicos (...) alocam aquele tanto, controlam todo aquele tráfico, tomam todas aquelas decisões pelos estudantes" (idem, p. 164). $\mathrm{O}$ que deve ser enfatizado aqui é que o princípio de coordenação do mercado tem se tomado o instrumento central de coordenação em alguns sistemas nos quais previamente a coordenação era compartilhada e/ ou disputada pelo Estado e pela academia.

O modelo do Triângulo da Coordenação reconhece que fatores históricos e culturais agem para fazer o sistema de educação superior uma expressão da sociedade na qual ele está situado. Clark argumenta que coordenação e autoridade resultam daqueles três sistemas de forças que apresentam diferentes ou mesmos interesses e formas de funcionamento contraditórias. Eles não são, contudo, independentes, mas interligados no sentido de que grandes mudanças em um pólo do triângulo poderão provocar de certa forma mudanças nos outros pólos. A autoridade estatal aparece como a maior força, definindo a forma e as funções do sistema de ensino supenior e, consequentemente, definindo a maneira e a extensão do poder de coordenação do mercado sobre os destinos e comportamentos das instituições de ensino superior.

A idéia da autoridade estatal como sendo a principal força definindo a forma do sistema de ensino supenior pode também ser extraída de Clark, quando ele observa que "os mercados (...) são crescentemente formados pelas políticas e sanções da autoridade estatal" (idem, p. 170). O Estado forma o mercado por meio de subsídios (entre outros instrumentos de política educacional). Por intermédio de bolsas de es- 
tudo ou financiamento, o Estado "fortalece o poder dos consumidores" e, ao mesmo tempo, influencia a dinâmica do mercado de ensino supenor. Na visão de Clark, este método de financiamento é a antítese dos modelos de financiamento estatal por meio de transferências de recursos diretamente para as instituições, uma vez que essas transferências tomam as instituições "independentes dos consumidores" (idem, ibid.). A figura abaixo representa essa dinâmica.

\section{Figura 2}

(Dois Modelos de Financiamentos e Coordenação do Mercado)

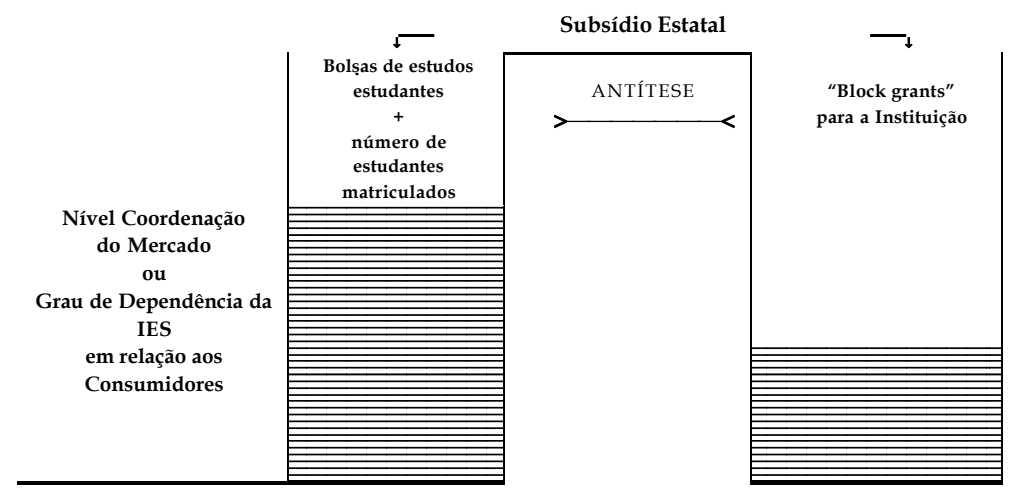

O Estado define como o mercado deve coordenar a educação superior não apenas por meio de subsídios, mas também por meio de outros mecanismos competitivos. Como referido logo acima, no modelo de Clark, o mercado é apresentado como a antítese da autoridade estatal. "A coordenação do mercado trabalha sem se beneficiar de uma superestrutura" (1983, p. 162). Deve-se observar, contudo, que o mercado na educação superior não é a antítese da coordenação estatal, mas o desenvolvimento da ação deste último. ${ }^{3} \mathrm{O}$ Estado (ou o govemo) estabelece as condições e as estruturas por meio das quais a coordenação do mercado opera. Neste sentido, o mercado beneficia-se de uma superestrutura. Isso ocorre porque o Estado e alguns sistemas de ensino superior, como os do Reino Unido e da Austrália exemplificam (Williams, 1997; Margnson, 1997; Miller, 1995; Gomes, 2000a), estão grandemente envolvidos no processo de troca, dado que eles se apresentam como o grande consumidor, tomando as "decisões corretas". As- 
sim, deve-se também observar que a introdução de mecanismos de mercado como instrumentos de coordenação e controle é um produto de decisões políticas. É papel do Estado mudar seu relacionamento com os setores e as instituições de ensino superior. "Troca" - Clark (1983, p. 162) argumenta - "é a forma básica de interação que se coloca em contraste com o comando da autoridade estatal". De fato, essa é uma visão datada. Desde inícios dos anos de 1980, o Estado, em alguns países mais do que em outros, tornou-se ele mesmo um agente do processo de troca, embora ele seja um agente qualitativamente diferente dos outros agentes presentes no mercado.

\section{As novas linhas estruturais do Sistema de Ensino Superior Brasileiro}

Esta secção objetiva apresentar as novas linhas estruturais e operacionais que caracterizam o Sistema de Ensino Superior Brasileiro (SESB) como resultado do projeto de reestruturação da educação superior dos governos Femando Henrique Cardoso. Estamos usando o termo linhas para indicar o caráter aberto, de processo a constituir-se e a definir-se como produto da implementação do projeto de reforma da educação superior. Como um dos objetivos deste artigo é demonstrar que o processo de reestruturação está em progresso, é, então, assumido que uma nova estrutura está emergindo da anterior. Algumas linhas dessa nova estrutura podem ser identificadas de forma mais consistente que outras e, nesse trabalho de identificação, iremos especificar diferenças com relação aos setores federal e particular.

\section{Diversificaçãoinstitucional}

Diversificação institucional constitui um dos aspectos centrais da nova estrutura do SESB. A estrutura anterior consistia de um tipo ideal de universidade de pesquisa que veio a se materializar, formalmente, como modelo único, caracterizado por. 1) o ensino superior deveria ser ensinado predominantemente em universidades e apenas excepcionalmente em instituições não-universitárias e b) o ensino superior deveria obedecer ao princípio da unidade entre ensino e pesquisa. Essa última característica continua como elemento definidor da universidade brasileira, ao passo que o caráter de excepcionalidade da existência de estabelecimentos não-universitánios, presente a partir da Reforma Universitária de 1968, foi substituído pelo reconhecimento e pela proteção oficial. Duas novas instituiçõ̃es de educação 
superior passam a existir oficialmente a partir de dezembro de 1996: a universidade especializada por campo de saber e o centro universitário. Todas as instituições de ensino superior (ver Figura 3 abaixo) oferecem cursos de graduação, ao passo que o desenvolvimento de pesquisa e os cursos de pós-graduação (mestrado e doutorado) permanecem altamente concentrados nas universidades públicas federais e estaduais, e em algumas poucas universidades particulares.

\section{Figura 3}

(Tipos de Instituições de Educação Superior. A “Metáfora da Escada”)

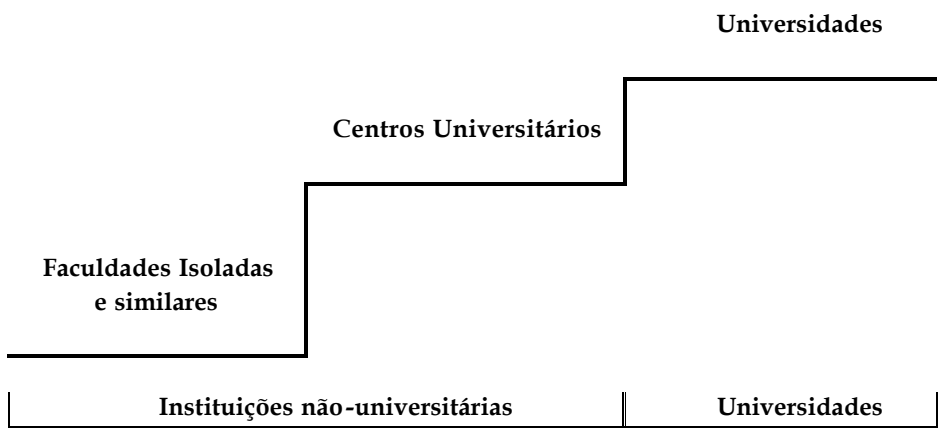

A "metáfora da escada" contribuirá para o entendimento da dinâmica subjacente ao processo de diversificação institucional. O CNE não estabeleceu a diversificação institucional como uma força estática do SESB. Muito pelo contrário, projetou-a como instrumento da política de coordenação e controle do MEC e da supervisão do CNE, para dirigir a dinâmica interna do funcionamento e da expansão do sistema. Neste contexto, dinâmica interna significa a real possibilidade, dentro dos critérios, requerimentos e incentivos estabelecidos, de as faculdades isoladas e similares buscarem o status de centro universitánio, e destes, o status de universidade. As chaves operacionais da dinâmica intema residem, por um lado, no processo de avaliação regular, no (re-)credenciamento periódico e no projeto institucional de apropriação dos atributos da autonomia universitária (Brasil, 1997) e, por outro lado, na vontade e no poder político do ministro. Esses aspectos são essenciais para o entendimento do espírito da política educacional reinante no Brasil, na qual a avaliação é associada a prêmios ou 
punições. Pensando em termos dos setores do ensino supenior, o setor privado - cuja magnitude e importância numérica, ${ }^{4}$ e por isso o valor das relações de troca que perpassa o negócio (business) do ensino superior privado, sua atividade predominante - tende a ser diretamente afetado e desafiado por essa lógica de promoção de statusinstitucional.

Um segundo ponto que deve ser colocado com relação à noção de diversificação institucional advogada pelo MEC diz respeito à ausência do "critério número de alunos matriculados" para se definir uma instituição de ensino superior, como foi aplicado, por exemplo, o "tamanho" mínimo de 2.000 estudantes para que uma instituição de ensino superior se tomasse membro do sistema nacional unificado produzido pela política de reestruturação da educação superior na Austrália (Taylor, 1991, p. 203). ${ }^{5}$ No caso brasileiro, identifica-se, para cada tipo de instituição, seja universidade, centro universitário ou faculdades isoladas e similares, uma grande variedade de tamanho institucional e da qualidade do ensino ofertado.

\section{Coordenaçãoecontrole}

O MEC passou a ser a principal agência de coordenação, controle e decisão política do SESB, ao passo que o CNE Se tornou um órgão consultivo e credenciador. É importante lembrar que o último teve suas funções redefinidas pelo primeiro para constituir-se em agência "guardiã da qualidade do ensino", sem grande poder de ação e intervenção sobre outras questões ou problemáticas da educação superior. É relevante notar também, com a ajuda de Becher \& Kogan (1992, p. 184), que a retórica da "garantia da qualidade" é parte do discurso mercantilista da educação superior e se contrapõe à noção de "controle da qualidade", que faz parte do discurso burocrático-administrativo. Esta distinção é importante porque ratifica a hipótese de que o governo federal fortalece a potência de coordenação dos mecanismos de mercado, ao passo que o MEC (SESU) e o CNE buscam "garantir" a qualidade da oferta da educação superior por meio de instrumentos como o Exame Nacional de Cursos e a Avaliação das Condições de Oferta de Cursos, que caracterizam a política de avaliação do MEC (Gomes, 2001).

Parece necessário, neste momento, oferecer uma definição de coordenação em função de sua relevância para os argumentos levantados mais abaixo. Em primeiro lugar, todo e qualquer processo de coordenação implica a existência deagênciaseagentes. Esses são sempre guiados por interesses e motivações específicas e/ ou particulares, e no 
caso de uma agência, como, por exemplo, o Estado, interesses e motivações revelam ou articulam-se com projetos político-ideológicos. Em segundo lugar, a pressuposição da existência de interesses e motivações particulares na verdade revela a existência de interesses, motivações e projetos político-ideológicos diferentes, divergentes ou contraditónios. Neste sentido, coordenação não deve ser compreendida como co-operação harmônica entre diferentes partes, mas como compartilhamento de poder.

O conceito de coordenação necessita ser emancipado de sua carga positivista e instrumentalista e, por isso, deve ser re-escrito a partir de uma perspectiva crítica. Um primeiro passo nessa direção é dado se coordenação for definida como relações de poder em ação, as quais são por sua vez condicionadas por projetos político-sociais e pela ação de grupos de interesses "infiltrados" no Estado e nas suas agências que lidam com educação supenior. Tais relações depoder em ação não deixam de se articular ou mesmo de serem determinadas por disputas e interesses que marcam o momento histórico de uma determinada sociedade e de sua economia. Esta compreensão é consistente com o conceito de Estado como entidade complexa, disputada, não-neutra, pluralmente constituída e estrategicamente motivada, que traz no seu seio as contradições e os dilemas intrínsecos da sociedade na qual se insere (Gomes, 2000a, p. 83).

Contudo, há ainda outra importante justificativa para repensarmos o conceito de coordenação no campo educacional, qual seja, que política educacional não existe fora da "esfera pública" (Habermas, 2000). Com efeito, todo e qualquer nível do sistema educacional, de natureza pública ou privada, está condenado a manter um relacionamento especial com 0 Estado ${ }^{6} \mathrm{em}$ uma sociedade democrática e, assim, a transformação de instituições de educação superior deve ser introduzida na forma de um esforço de ações coordenadas do govemo e das instituições. Coordenação é assim vista como arena política para o exercício da barganha e do conflito legitimado (Gomes, 2000c, p. 3).

Coordenação não ocorre como uma abstração dentro da arena política de conflito legitimado. A luta que marca as relações de poder daqueles envolvidos nos processos de coordenação não está apenas informada por interesses particulares e projetos político-ideológicos, mas também por concepções acerca dos "modos de coordenação". Segundo Clarke \& Newman (1997, p. 5), "modos de coordenação" são "complexos de regras, papéis e princípios reguladores em tomo dos quais as práticas sociais de organizações são estruturadas - que geram 
padrões típicos de relações sociais intemas e extemas e que, entre outras coisas, privilegiam certos tipos de conhecimento".

Como existem diferentes agências coordenadoras, o modelo triangular elaborado por Clark (1983) sugere diferentes formas de coordenação, quais sejam, o Estado, a academia e o mercado, cada um exprimindo "padrões típicos de relações sociais internas e extemas". O modelo de potência de coordenação apresentado logo abaixo - denominado "Metáfora da Flutuação" - não apenas acrescenta uma quarta força coordenadora ao Triângulo da Coordenação de Clark como também empreende esforço analítico para identificar mecanismos e instrumentos por meio dos quais a coordenação se realiza no SESB. No modelo aqui proposto, o Estado ocupa a posição central e estratégica como agência de coordenação e controle na sociedade capitalista contemporânea.

Instrumentos e mecanismos de coordenação e controle

É relevante considerar, como parte da nova estrutura do SESB, OS principais instrumentos e mecanismos por meio dos quais coordenação, controle e monitoramento se materializam com relação aos setores federal e particular do ensino superior. $\mathrm{O}$ entendimento em tomo dos mesmos vem a ser importante para a seguinte hipótese: 0 MEC redefiniu suas funções e refinou seus instrumentos e métodos de intervenção sistêmica visando a fortalecer sua capacidade de govemar e visando a maximizar o desempenho do sistema de ensino superior como um todo.

A Figura 4 apresenta quatro vetores de coordenação no lugar dos três do Triângulo da Coordenação formulado por Clark (1983). A novidade aqui é a forma institucional de coordenação que constatamos ser uma força particularmente presente no caso do ensino superior brasileiro. ${ }^{7} \mathrm{~A}$ presença no cenário político nacional de um número crescente de associações nacionais que representam as instituições federais (ANDIFES), privadas (ANUP, ABMES, SEMESP/SP), privado-católicas (ABESC, ANAMEC), comunitárias (ABRUC, NASC) e estaduais, possuidoras de potências consideráveis de poder que não podem ser reduzidas à fatia de poder que normalmente atribuímos à comunidade acadêmica - a academia, do modelo clarkiano - , constitui justificativa razoável à reflexão sobre a forma institucional de coordenação. Se alguém persiste em reduzir o poder dessas associações nacionais à força política da academia, superestima, em sua análise, o poder acadêmico no 
Brasil, e, ao mesmo tempo, subvaloriza a dimensão do lobby político das associações representativas das instituições particulares e federais.

Para pensar a dinâmica de coordenação e controle do ensino supenior no Brasil, trabalha-se aqui com a tese de graus variados de potencial de coordenação, aos quais serão atribuídos determinados valores que simbolizam potências (de coordenação), e que variam de: 'ausência de mecanismos de coordenação $=0$ ', 'fraco potencial de coordenação $=1$ ', 'médio potencial de coordenação $=2$ ' e 'forte potencial de coordenação $=3$ '. Esses valores atribuídos são derivados da análise de quatro instrumentos ou mecanismos especificamente relevantes para cada forma de coordenação, isto é, do Estado, do mercado, da academia e da forma institucional. Os valores (de 0 a 3 ) de potência de coordenação e controle são aplicados para cada um dos quatro instrumentos ou mecanismos, e a soma deles será usada para indicar os potenciais de coordenação distribuídos numa escala que varia de 0 a 12, e que tem a seguinte subdivisão: 0 a $4+$ significa fraco potencial de coordenação; 5 a 8+ significa médio potencial e 9 a 12+ significa forte potencial de coordenação (ver Figura 4 em seguida). A partir daí distribuímos comparativamente o potencial de coordenação relativo ao Estado, ao mercado, à academia e à forma institucional em uma "imagem flutuante", na qual posicionamos os setores federal e privado (ver Figura 5).

Nessa formulação analítica de instrumentos e potencial de coordenação, incorporamos o postulado foucaultiano (Foucault, 2000, p. 11) que informa que "não há relações de poder sem resistências". Coordenação é o resultado de relações de poder que são, por sua vez, condicionadas por projetos políticos conflitantes e pelas ações daqueles envolvidos no campo do ensino superior em particular, e por interesses e disputas que afloram na sociedade como um todo.

\section{Instrumentosdecoordenação estatal}

Os quatro instrumentos que estruturam o potencial de coordenação e controle do Estado com relação à educação superior federal e privada são: 1) financiamento; 2) nomeação dos dirigentes das universidades, dos diretores de instituições não-universitárias e controle dos processos de contratação/nomeação de professores e servidores das IES; 3) avaliação das IES; e 4) autorização de cursos e credenciamento e re-credenciamento das instituições (Figura 4).

Não resta dúvida de que o atual sistema de financiamento das instituições federais tem potência média de coordenação para o go- 


\section{Figura 4}

\section{Poder de Coordenação e Controle sobre Setores Federal e Privado exercidos por Estado, Mercado, Academia e Forma Institucional}

\begin{tabular}{|c|c|c|}
\hline \multirow[t]{2}{*}{ Formas e Instrumentos de Coordenação e Controle } & \multicolumn{2}{|c|}{$\begin{array}{l}\text { Potencial de } \\
\text { Coordenação }\end{array}$} \\
\hline & Federal & Privado \\
\hline $\begin{array}{l}\text { Estado } \\
\text { 1. Financiamento (formas de pagamento de salários e contratos) e } \\
\text { mecanismos de racionalização/controle e otimização do uso dos } \\
\text { recursos públicos }\end{array}$ & $\begin{array}{c}11+ \\
2\end{array}$ & $\begin{array}{l}7+ \\
1\end{array}$ \\
\hline $\begin{array}{l}\text { 2. Nomeação de reitores e controle dos processos de } \\
\text { contratação/nomeação dos professores e servidores }\end{array}$ & 3 & 0 \\
\hline 3. Sistema de avaliação dos estudantes, cursos e instituições & 3 & 3 \\
\hline $\begin{array}{l}\text { 4. Autorização periódica dos cursos, e credenciamento e } \\
\text { recredenciamento periódico das instituições }\end{array}$ & 3 & 3 \\
\hline Mercado & $2+$ & $9+$ \\
\hline $\begin{array}{l}\text { 1. Financiamento (taxas escolares, mensalidades, o novo sistema de } \\
\text { financiamento estudantil) }\end{array}$ & 1 & 3 \\
\hline $\begin{array}{l}\text { 2. Práticas e estratégias de competição pelos estudantes ou/e a } \\
\text { busca do lucro }\end{array}$ & 0 & 3 \\
\hline $\begin{array}{l}\text { 3. O fortalecimento do poder de decisão e escolha do estudante } \\
\text { cliente/consumidor (baseado nas informações geradas pelas } \\
\text { procedimentos de avaliação como o Provão: comparação dos } \\
\text { indicadores de desempenho e a classificação das mesmas em } \\
\text { rankings) }\end{array}$ & 0 & 2 \\
\hline 4. Parcerias com os setores econômicos (prestação de serviços) & 1 & 1 \\
\hline Academia & $9+$ & $2+$ \\
\hline 1. A natureza do contrato do pessoal acadêmico & 2 & 0 \\
\hline $\begin{array}{l}\text { 2. Participação nos subsistemas de financiamentos de pesquisa e nos } \\
\text { procedimentos de avaliação, nos conselhos editoriais de } \\
\text { periódicos, nas associações acadêmicas e inserção na cultura e na } \\
\text { tradição acadêmico-profissional }\end{array}$ & 3 & 1 \\
\hline $\begin{array}{l}\text { 3. Nomeação de reitores, diretores de centros e chefes de } \\
\text { departamentos }\end{array}$ & 2 & 0 \\
\hline $\begin{array}{l}\text { 4. O poder de associações acadêmicas e profissionais para influenciar } \\
\text { as políticas educacionais para o ensino superior }\end{array}$ & 2 & 1 \\
\hline Institucional & $8+$ & $10+$ \\
\hline 1. Poder dos mantenedores em nível institucional & 2 & 3 \\
\hline $\begin{array}{l}\text { 2. Poder dos associações dos mantenedores ou associação } \\
\text { representativas das IES em nível nacional }\end{array}$ & 2 & 3 \\
\hline 3. Poder de indicar/nomear/contratar reitores e outros gestores & 1 & 3 \\
\hline 4. A distribuição do poder acadêmica em nível da IES & 3 & 1 \\
\hline
\end{tabular}

Símbolos: 'forte potencial de coordenação $=3$ ', 'médio potencial $=2$ ', 'fraco potencial $=1$ ' e 'ausência de mecanismo de coordenação $=0$ '. 
vemo. Para aumentar sua potência de coordenação e controle, o governo vem tentando mudar a sistemática de financiamento das universidades federais (Brasil/MEc, 1996a, 1999a, 1999b, 1999c; Brasil, 1996b; Gomes, 2000b), vista como ineficiente e inflexível, porque esta não funciona de acordo com a "economia das matrículas". A capacidade do govemo para coordenar e controlar as instituições federais cresceu recentemente em razão da introdução da GED, um dispositivo que vincula desempenho ou produtividade a salánios dos professores. Porém, a situação perfeita seria, de acordo com o projeto govemamental para as instituições oficiais, se o modelo de "autonomia contratual" (Neave, 1988) fosse implementado e todas as universidades federais adenissem a ele, segundo as regras estabelecidas pelo MEC (Brasil/MEC, 1999a). Pura fantasia, porque isso equiparia o MEC com incomparável poder de coordenação e controle sobre as federais. Ressalte-se, pois, que a questão da autonomia universitária das instituições federais é um dos mais claros exemplos de que coordenação sintetiza relações de poder e reflete as tensões da luta política dentro do setor público federal no Brasil.

Com relação ao setor privado, defende-se a tese de que o govemo gostaria de ter maior potencial de coordenação e controle sobre esse setor, baseado no critério financiamento, do que o realmente existente no presente. Tal iniciativa política é muito difícil de ser implementada em conseqüência da determinação constitucional que expressamente proíbe a aplicação de recursos públicos para financiar a educação privada. Assim, pode-se dizer que atualmente o potencial de coordenação e controle govemamental com relação às instituições privadas, baseado no mecanismo financiamento, varia de fraco para uma completa ausência de mecanismos. Tendo dito isto, contudo, não significa dizer que a gestão de Paulo Renato não tem pensado e tomado decisões no sentido de intervir ou favorecer as relações econômicas daqueles que fazem parte do setor privado. Pelo menos duas iniciativas merecem ser citadas aqui. Em primeiro lugar, o governo criou um programa (com recursos do Banco Nacional de Desenvolvimento Econômico e Social - BNDES) para emprestar dinheiro às universidades privadas, o qual se encontra em funcionamento desde 1997. A justificativa para a existência desse programa é melhorar a oferta dos serviços dessas universidades em termos de infra-estrutura, laboratórios etc. Em segundo lugar, o velho Programa de Credito Educativo foi transformado em ou substituído por um programa de empréstimo para financiar estudantes especificamente matriculados em instituiçõesnão-públicas de educação superior que tenham sido positivamente avaliadas pelo Exame Nacional de Cursos (Brasil, 
1999c). Segundo a retórica oficial, instituições de ensino superior que matriculam estudantes pertencentes ao programa de empréstimo devem apresentar um bom desempenho no "Provão", caso contrário, elas serão desautorizadas a ter alunos do refenido programa.

O Exame Nacional de Cursos vinculado ao financiamento por empréstimo combina, na verdade, a coordenação estatal com os mecanismos de mercado. Mas é o MEC, mais que os estudantes, que desempenha, como Williams (1997, p. 277) observa com relação ao governo para o contexto britânico, o papel de consumidor guardião (surrogate customer). Assim, o programa de financiamento estudantil apresenta-se como um primeiro passo no sentido de fortalecer o potencial de coordenação e controle governamental sobre as instituiçõ̃es privadas, além de fortalecer a própria privatização da oferta de ensino superior no país.

Com relação à nomeação/contratação de reitores, diretores e professores, o govemo tem um grande potencial de controle no setor federal ao passo que está completamente ausente no caso das instituições privadas. Para oferecer exemplos de como o ministro Paulo Renato tem colocado em prática esse instrumento de poder, relembremos, caro leitor, que em seis universidades federais (UFRPE, UFPA, UFMA, Uni-Rio, UFBA e UFRJ) os candidatos aos postos de reitor e vice-reitor que foram escolhidos pela maioria dos membros das respectivas comunidades universitárias não chegaram a assumir os seus postos porque o ministro Paulo Renato, que detinha em última instância o poder legal de nomeação, nomeou candidatos de sua preferência e que receberam menos votos nos processos de escolha realizados nas referidas universidades. Estes são exemplos razoáveis do que nós temos denominado da forma política de coordenação govemamental em oposição à forma burocrática estatal de coordenação e controle previamente utilizada.

A avaliação das IES, que nesse governo tomou a forma de avaliação de resultados (indicadores de desempenho), e a lógica presente nos processos formais de autorização e (re)credenciamento constituem instrumentos indissociáveis de coordenação e controle estrategicamente desenvolvidos pelo MEC e conjuntamente manipulados pelo MEC (SESU $\mathrm{e}$ INEP) e pelo CNE. Esses instrumentos expressam uma forte potência de coordenação e controle relativamente aos setores federal e privado.

\section{Mecanismosdemercado}

A discussão sobre a coordenação do e pelo mercado focaliza os seguintes quatro mecanismos: 1) financiamento; 2) competição 
institucional por estudantes; 3) o poder dos usuários ou clientes educacionais; e 4) parceria entre IES e setores produtivos da sociedade. No Brasil, assim como em outras formações sociais, as novas formas de que a coordenação estatal tem se revestido justapõem, e em muitos casos confundem-se, com os mecanismos de mercado. As razões para isso residem nas estratégias govemamentais para incorporar a "lógica de mercado" como instrumento de governança dos sistemas educacionais. Mesmo assim, ou por isso mesmo, é possível indicar como esses quatro mecanismos de mercado possuem um grau razoável de potência coordenadora (ver Figura 4).

Se as instituições federais são financiadas pelo Tesouro Nacional por meio de impostos cobrados à população e, portanto, não existe a cobrança de taxas escolares, pode-se então concluir que a dinâmica de mercado se apresenta com fraco potencial de coordenação neste setor. (Não devemos, contudo, esquecer que as IFEs estão presentes em todas as regiões do país e que têm historicamente trabalhado com base no princípio de satisfazer a demanda social por educação superior de suas respectivas regiões.). $\mathrm{O}$ sistema de financiamento do setor privado é completamente diferente daquele do setor federal, uma vez que ele é fundamentado em valores (relações) de troca por meio dos quais os estudantes são essencialmente percebidos como compradores que pagam por produto educacional, e as instituições de ensino privadas, como vendedoras credenciadas de serviços educacionais. Essas relações de troca envolvem, teoricamente, atores econômicos livres. Pode-se advogar que a lógica econômica dastaxasescolares possui um forte potencial de coordenação no setor privado.

Como a sobrevivência (e o lucro) de uma instituição de ensino superior depende das taxas escolares cobradas aos seus clientes, pode então ser presumido que a competição entre as instituições por mais clientes (de onde decorre a mais-valia educacional) tem um médio mais que um forte potencial de coordenação.

Atribuímos à competição um médio potencial de coordenação porque a cultura de escolha do consumidor, dentro do SESB, acaba de receber seu maior estímulo, que foi o estabelecimento do sistema de informação alimentado pelos resultados dos procedimentos de avaliação realizados anualmente pelo MEC (Exame Nacional de Cursos e Avaliação das Condições de Oferta de Cursos). A publicação e a posterior utilização dos resultados das avaliações foram planejadas para funcionar como "mediadores" das relações de troca no mercado do ensino superior. Um outro fator que nos leva a atribuir à competição um médio 
potencial de coordenação é a existência de um excedente de demanda para a educação superior no Brasil, exceção talvez para os estados de São Paulo e Rio de Janeiro, nos quais a oferta concentrada de cursos em algumas áreas vem produzindo uma verdadeira "guerra comercial" pelos "clientes" e, como conseqüência, produzindo a queda dos preços das mensalidades de algumas instituições competidoras.

Mas é importante considerar que, entre a publicação e circulação de informações acerca do desempenho de cursos e instituições e seu efetivo uso pelos atuais e futuros estudantes/clientes, opera a variável tempo. A população estudantil (incluindo pais e outros financiadores da educação privada) não constitui ainda uma "unidade", pois é formada por uma multiplicidade de atores movidos pelos mais vaniados interesses, onentados para o "mercado", que se encontram engajados em atividades díspares e que, como coletivo, não têm praticamente nenhum poder de negociação. Um importante dado que se contrapõe à tese govemamental de estudantes de graduação agindo como consumidores ou agentes econômicos aplicadores da teoria da escolha racional, dado esse que pode eventualmente destruir as pretensões dos reformadores oficiais do ensino superior, é que mais de 60\% desses estudantes estão matriculados em cursos noturnos (Brasil/MEC/INEP, 1999). Isso é um indicador de que a grande massa desses estudantes faz parte da população trabalhadora diurna, que utilizam parte considerável de seus salánios para pagar as taxas e mensalidades das IES em que estudam e que, em contrapartida, não dispõem de tempo para formara "comunidade estudantil" dentro das respectivas instituições. Com efeito, eles não perceberão, ou talvez só o façam individualmente, que os mecanismos de mercado representam uma potência de coordenação e controle das iEs onde estudam.

O último mecanismo de coordenação pelo mercado é a parceria com os setores da economia, o qual pode ser classificado como tendo um fraco potencial de influência na agenda dos setores federal e privado. Contudo, verifica-se um crescimento de uma consciência dos vários grupos de professores pesquisadores e/ ou pesquisadores-professores em tomo da necessidade de se desenvolverem parcenias com os setores produtivo e terciário da economia. As universidades federais, como o centro nervoso da produção científica e acadêmica brasileira, encontram-se em excelente posição para liderar, como o fazem em algumas trincheiras, programas inovadores em várias áreas do desenvolvimento social, econômico, cultural e educacional, ao passo que o setor privado, com rańssimas exceções, tem um fraco potencial para responder a outras demandas que não aquelas associadas com atividades de ensino e consul- 
toria. Todavia, a discussão sobre parcerias, ou sobre a relação universidade/empresa, não recebeu a devida atenção de gestores, professores e estudantes das universidades federais. Os mitos e tabus que recobrem essa questão têm facilitado a privatização invisível das universidades federais.

\section{Coordenaçãoacadêmica}

Quatro aspectos parecem dominar a discussão do potencial de coordenação e controle denivado da comunidade acadêmica: 1) a natureza do contrato de trabalho do pessoal acadêmico; 2) a participação no sistema de pares e comissões nacionais; 3) a participação no processo de escolha dos dirigentes das IES (reitores, diretores de centros e chefes de departamentos etc.) e 4) o grau de organização das associações acadêmica e profissional no âmbito nacional.

A natureza do contrato de trabalho no setor federal define seu pessoal acadêmico como estratégico para o desenvolvimento ou os objetivos de longo alcance do Estado nacional (coisa muito anterior a esse govemo) e, portanto, investiram-no de uma potência política para interferir diretamente nos destinos da educação superior, inclusive na pesquisa, independentemente das políticas para o setor desse ou daquele governo. A política de reforma do Estado do primeiro Governo Fernando Henrique Cardoso, sob a chefia de Bresser Pereira no Ministério da Administração e Reforma do Estado (o extinto MARE), criou possibilidades de flexibilização dos contratos de trabalho e introduziu medidas que permitem demissões dos servidores, desde que baseadas em processo de avaliação de desempenho. Apesar dessas mudanças, o pessoal acadêmico, depois de três anos de trabalho efetivo, goza de estabilidade no emprego, e sua promoção passou a ser vinculada à avaliação de desempenho. Embora o governo federal tenha introduzido a GED como instrumento que associa salário à avaliação de produtos, isso não alterou fundamentalmente a natureza das relações de trabalho entre Estado e professores. O pessoal acadêmico das universidades federais tem considerável controle sobre quase todos os aspectos da vida acadêmica, incluindo seleção de novos professores, gestão (colegiada), planejamento, ensino, pesquisa, entre outros aspectos.

A situação é muitíssimo diferente no setor privado. Ao contrário do setor federal, se nos basearmos nos termos dos contratos de trabalho e se olhamos para a situação da grande maioria dos professores empregados nas instituições privadas, é possível afirmar que eles (in- 
dividual ou coletivamente) possuem poderes mínimos de coordenação e controle. Eles não têm poder, em nível departamental, de decisão sobre contratação e manutenção de professores. $O$ controle é da mantenedora. ${ }^{8}$ Um olhar, mesmo que superficial, nas estatísticas do setor privado levanta profundas preocupações a respeito da frágil natureza dos seus professores como categoria profissional. O setor privado empregava em tomo de 79.384 professores no ano de 1998. Eles estavam divididos em três grupos que se diferenciam em função do contrato de trabalho: 12.068 eram professores com tempo integral, 20.597 com dedicação parcial e 46.719 professores "horistas" (pagos por horaaula). ${ }^{9}$ Nesse setor não existe a regra da estabilidade no emprego, porque as relações de trabalho são regidas pela Consolidação das Leis Trabalhistas. Focalizando apenas sobre os professores "horistas", que representavam 58,8\% do total de professores empregados no setor privado em 1998 - muito embora a observação que segue se aplique também para as demais categonias de professores - , é relevante notar que a natureza do contrato de trabalho em questão é extremamente precária, assim como o são suas condições de trabalho, o que beneficia particularmente os proprietários das instituições privadas em detrimento dos estudantes e do pessoal docente. Assim, é muito difícil pensar esse coletivo de professores como sendo o que geralmente entendemos, mesmo que de forma muito superficial, um corpo acadêmico ou comunidade acadêmica e, conseqüentemente, como possuindo algum grau ou potencial de autonomia e coordenação dentro do sistema como um todo. Na outra face da moeda encontra-se o forte poder de controle e coordenação manipulado por mantenedores individuais, em nível institucional, e, em nível nacional, por suas associações e sindicatos.

O número de professores e/ ou pesquisadores vinculados às instituições federais e/ ou privadas envolvidos em comissões (tais como do Exame Nacional de Cursos, da Avaliação das Condições de Oferta de Cursos, Autorização de Cursos e Credenciamento de Instituições, Comitê Assessor do PAUUB, das Comissões de Áreas para Avaliação dos Periódicos Científicos, das Comissões de Pares da CAPES e do CNPQ envolvidos no financiamento de pesquisa e concessão das diversas modalidades de bolsas de estudo, entre outras associações nacionais científicas e acadêmicas não ligadas ao aparelho estatal) representa um indicador não desprezível do potencial de coordenação derivando da participação acadêmica no sistema de pares. Infelizmente os dados que conseguimos reunir até o presente são muito limitados nesse sentido. Contudo, podemos trabalhar por exclusão, ou seja, o grande 
número de professores horistase com tempo parcial sugere que eles não se qualificam ao convite para participar naquelas comissões. Acrescentese a esse dado o relativamente pequeno número de professores das instituições privadas envolvidas em pesquisa e apresentação dos seus resultados em congressos de referência nas respectivas áreas, assim como o pequeno número de doutores no corpo docente dessas instituições, critérios estes utilizados por agências e associações que levam à participação nas comissões nacionais. Existiam, por exemplo, em tomo de 126 acadêmicos envolvidos na preparação da edição de 2000 do Exame Nacional de Cursos, distribuídos em 18 comissões de cursos (7 em cada uma). Desses, 66 pertenciam às universidades federais e em tomo de 22, às instituições privadas (Brasil// MEC/INEP, 2000). Os Comitês Assessores das edições do PAUIB, como sua própria criação nos idos de 1993/94, e muitas das principais comissões e associações nacionais são formados majoritariamente por pesquisadores docentes das universidades federais e estaduais. Tal participação revela-se importante indicador de que ao passo que o potencial de coordenação acadêmica do setor federal com relação ao sistema é elevado, ele é muito fraco no setor privado, quando tomamos como base de análise a composição do sistema de pares.

Ao pessoal acadêmico das federais pode-se também atribuir um médio potencial de coordenação/controle sobre os sistemas de escolha de reitores, diretores e chefes de departamentos, sistemas esses marcados por uma forte prática de decisão colegiada. Esse sistema de organização do poder acadêmico veio sendo criticado e desafiado pelo ministro Paulo Renato que, como apontamos acima, tem exercido seus poderes legais para nomear reitores que parecem estar em linha com o projeto govemamental para a educação superior. Isso tem tido algum efeito sobre o processo eleitoral da nova diretoria da ANDIFES, cujo presidente eleito pertencia ao bloco de oposição ao ministro (Silva, 2000). Ressaltemos novamente que isso reflete o forte potencial de organização e mobilização das associações acadêmicas, profissionais e sindicais das universidades federais, que contrasta com a fraca ou a ausência de coordenação e controle por parte dos professores empregados nas instituições privadas.

\section{Aforma institucional decoordenação}

A forma institucional de coordenação e controle apresenta muitos elementos comuns com a forma acadêmica, que exprime um forte potencial decoordenação (9+) no Brasil. O mesmo não é verdadeiro com relação ao setor privado, cujo potencial de coordenação acadêmica pode 
ser classificado como extraordinariamentebaixo (2+), divergindo drasticamente do potencial institucional de coordenação e controle que se apresenta como significativamente elevado tanto em nível institucional quanto no âmbito dos interesses de força que se dá em nível nacional. E necessário descrever a natureza e as origens desse forte potencial de coordenação por parte das associações representativas das entidades privadas da educação superior.

A forma institucional privada de coordenação é particularmente forte nas camadas administrativas de suas instituições; é das relações de trabalho entre mantenedor/instituição (empregador) e professores (empregados) de onde decorre seu poder. Ao passo que, por um lado, a frágil natureza dos contratos e das condições de trabalho, a ausência de poder colegiado autônomo, o baixo nível de qualificação docente e a forte presença dos mecanismos de mercados (entre outros fatores) minam o potencial de coordenação e controle dos professores do setor privado, por outro lado, o quase ilimitado poder dos mantenedores, gestores e administradores das instituições privadas, baseado em variados mecanismos de mercado, fortalece o poder de coordenação/controle institucional. Isso está diretamente ligado à ausência de meios institucionalizados por meio dos quais os professores poderiam ser muito mais influentes nos destinos das instituições onde eles trabalham. Um forte potencial de controle concentrado no nível administrativo contrasta com e parece ser o resultado do frágil poder "acadêmico" do pessoal docente do setor privado. Existem, contudo, poucas universidades privadas da importância da Puc-sp e outras Pucs, nas quais se verifica a existência de experiências notáveis de poder acadêmico.

Associações nacionais das instituições federais e privadas e seus representantes tendem a exercer influência constante sobre esferas estatais de formulação de políticas e de coordenação, regulação e controle das instituições, muito embora se deva reconhecer que as formas como aqueles setores expressam seus interesses e pressões guardam profundas diferenças. ${ }^{10}$ São formas diferentes de usar a potência "política" para influenciar as políticas setoriais formuladas pelo Estado (Congresso Nacional, Ministénio da Educação, CNE, entre outros).

\section{A dinâmica de coordenação e controle}

A Figura 5, formulada a partir da Figura 4, apresenta um modelo explicativo da dinâmica de coordenação e controle da educação superior no Brasil. Ele representa um esquema simplificado do po- 
tencial de coordenação associado ao Estado, à academia, ao mercado e à forma institucional. Os potenciais de coordenação e controle estão classificados em três categorias distribuídas numa escala imaginánia de 0 a $12+$. São elas: fraco potencial ( 0 a 4+), médio potencial ( $5+a$ 8+) e forte potencial de coordenação $(9+a$ 12+). Para a melhor compreensão do modelo, é necessário fazer um ou dois comentánios porque o denominamos de a "Metáfora da Flutuação". O modelo de "flutuação" inspira-se na imagem de colunas de ondas luminosas subindo e descendo no painel de um aparelho de som controlado por várias pessoas, cujas visões de mundo, opiniões, gostos, interesses, expectativas e formas de agir divergem, contrastam, combinam ou entram em conflito relativamente ao volume, ao tema, ao texto, à ordem, ao estilo musical etc.

Existem cinco colunas na Figura 5, quatro das quais flutuam em resposta às pressões, demandas, interesses etc. A primeira coluna (ao lado esquerdo) representa a escala de potencial de coordenação e controle, que é dividida em três níveis (ascendentes ou descendentes): fraco, médio e forte. As outras colunas simbolizam as quatro principais forças socioinstitucionais (Estado, mercado, academia e instituições) que desenvolvem, apropriam-se (de), disputam e/ou compartilham os meios e processos de coordenação e controle. Nenhuma dessas forças é monoliticamente constituída. Elas constituem arenas próprias nas quais grupos divergentes entram em conflito, disputam e/ ou negociam. Assim, seus potenciais de coordenação e controle são exercidos dentro e em tomo dos setores educacionais (aqui o federal [f] e o privado [p]) a que respondem ou se ajustando ou resistindo a políticas, programas, exigências e requisitos daquelas forças.

Contudo, os setores da educação superior são, por sua vez, espaços de coordenação e controle (acadêmicos) e, como o Estado, têm estabelecido diretos e importantes canais de comunicação com segmentos representativos da sociedade civil. O Estado, como a Figura 5 simboliza, ocupa as posições mais estratégicas e desempenha funções políticas centrais e insubstituíveis com relação à educação dentro das sociedades capitalistas contemporâneas. Não apenas ele está (política, financeira, administrativa e constitucionalmente) "equipado" para exercer direta coordenação, controle e acompanhamento do sistema de ensino superior, assim como possui os meios para condicionar e intervir de forma relativamente precisa na natureza, nos instrumentos e no potencial de coordenação das outras forças (acadêmica e mercado). Nossa tese é a de que o Estado não os determina, porque eles construíram diferentes graus de autonomia, e agem de acordo com regras e interes- 


\section{Figura 5}

A "Metáfora da Flutuação" do Poder: Coordenação e Controle

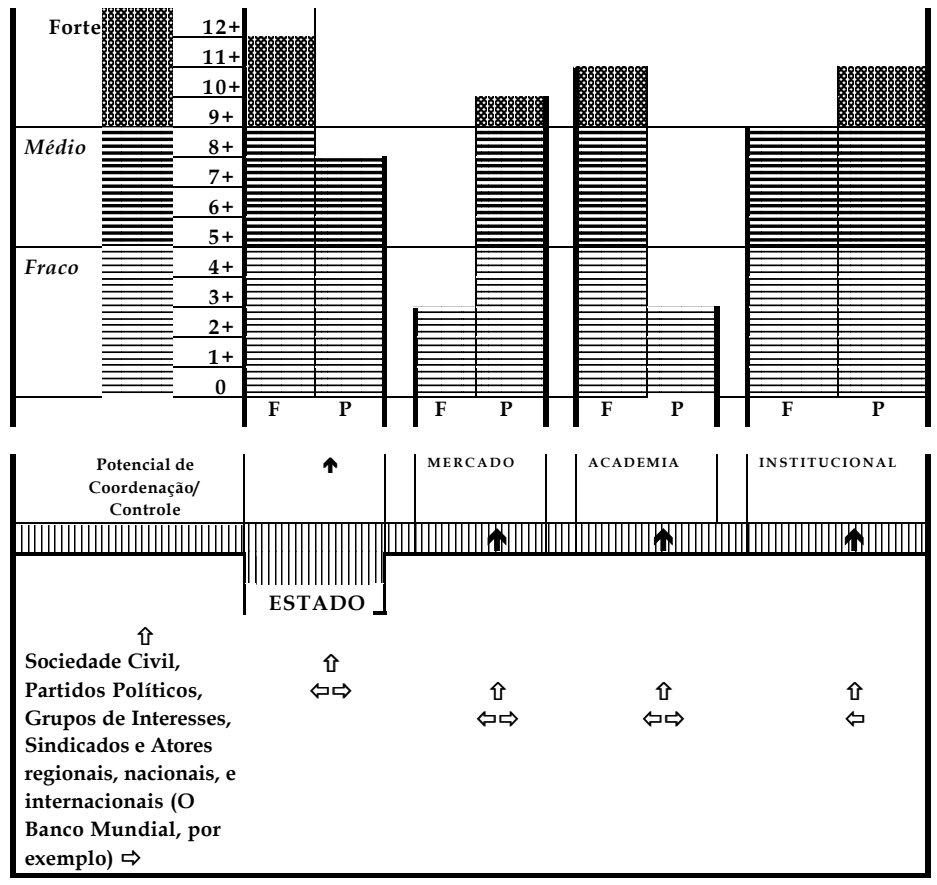

ses singulares. Porém, o Estado os regula por meios limitadores ou "libertadores", e por isso condiciona suas potências de coordenação e controle. Com efeito, é importante chamar a atenção para que o termo 'coordenação' tem sido usado aqui como a materialização de relações de forças. Acreditamos que a definição mais apropriada de relações de forças, capaz de incutir eficácia explicativa para a idéia de coordenação e controle dentro da "Metáfora da Flutuação", é aquela oferecida por Bernstein (1996, p. 19), que escreve que relações de poder "criam limites, legitimam limites, reproduzem limites entre diferentes grupos (...), diferentes categorias de discurso, diferentes categorias de agentes" e que, portanto, "poder sempre opera nas relações entre categorias" (grifos no original).

É oportuno revisitar brevemente a crítica que fazemos sobre a formulação original de Clark (1983), quando este afirma que a forma de 
coordenação pelo mercado é a antítese da coordenação realizada pelo Estado. A primeira "trabalha sem se beneficiar de uma superestrutura" (idem, p. 162). Como argumentamos, a forma de coordenação pelo mercado da educação supenior não representa a antítese da coordenação estatal, mas um desenvolvimento desta, que vem sendo utilizado pelo governo como um instrumento de governança. Na base da Figura 5, o Estado é posicionado de forma que simbolize o poder que tem para construir, expandir ou reduzir as formas de coordenação do mercado, da acadêmica e do institucional. A profundidade e a forma que essas forças coordenadoras podem vir a assumir dependem da existência regular de determinados fenômenos (políticos, econômicos, sociais, culturais, institucionais e ideológicos), que se imponham no cenánio nacional e intemacional, e dependem também da competência política (e/ou da força política) do govemo para negociare implementar seu projeto educacional para o sistema como um todo, ou para um setor em especial.

Uma breve discussão sobre a dinâmica de coordenação e controle com relação aos setores federal e privado é apresentada em seguida. Para um profundo entendimento dessa dinâmica, é imperativo realizar uma leitura comparativa das "colunas flutuantes" para verificar o equilíbrio/ desequilíbrio e/ou a existência de cooperação ou conflito entre as diferentes forças coordenadoras. A "Metáfora da Flutuação" reflete as relações de poder e controle, e corporifica, assim como as relações entre 0 Estado e a sociedade civil, "uma demarcação móvel, sujeita à construção e desconstrução contínuas" (Steinmetz, 1999, p. 25).

Setor Federal. O Estado é a principal agência de coordenação, controle e financiamento por trás do setor federal (forte potencial = $11+)$. Em contrapartida, a comunidade acadêmica das federais tem também forte potencial de coordenação e controle (9+) sobre seu próprio destino, e tem estado constantemente engajada na forma de uma resistência diária contra as políticas neoliberais dos govemos de Femando Henrique Cardoso, para manter sua capacidade de coordenação/controle. Parte da comunidade universitária federal tem lutado para assegurar certos privilégios estabelecidos, ao passo que outra parte, que discute e recusa tais privilégios, luta para manter o caráter público e gratuito da universidade federal brasileira, uma vez que entende ser este princípio fundamental para a preservação do patrimônio público que se coloca como estratégico para o desenvolvimento econômico e social do Brasil. $\mathrm{O}$ terreno em que a luta vem se dando é particularmente em torno das mudanças constitucionais e da reestruturação do Estado. $\mathrm{O}$ governo vem ampliando seu potencial de coordenação e controle, e um 
dos seus mais altos objetivos é fortalecer o potencial de coordenação do mercado (2+) com relação ao setor federal.

Muito embora a gestão de Paulo Renato tenha introduzido mecanismos de "avaliação" de desempenho visando à diferenciação salarial (GED), o efetivo uso de mecanismos de mercado somente será implementado se alguma forma de taxa escolar vier a ser introduzida no setor federal. É neste sentido que agências intemacionais, tais como o Banco Mundial e o Fundo Monetánio Intemacional, vêm pressionando o governo, mas os custos político-eleitorais de tais medidas têm-nas mantido no campo da política desejável, mas não implementável. Algumas diretrizes de uma política de fortalecimento dos mecanismos de mercado, tais como 1) eficiência administrativa baseada na teoria do custo/benefício, 2) pressão por uma liderança universitánia executiva forte, 3) incisivas chamadas para aumentar a social accountability no setor público, 4) indicação da "necessidade" de aumento da capacidade de resposta institucional às demandas sociais, mas, sobretudo, a do mercado, 5) e a pressão, particulamente por meio do subfinanciamento, para a diversificação das fontes de (auto)financiamento, entre outros aspectos, estão se tomando gradualmente parte da realidade discursiva e da prática administrativa dos reitores e pró-reitores das universidades federais. ${ }^{11}$

A forma institucional apresenta um médio potencial de coordenação no setor federal. Essa forma de força coordenadora é, sobretudo, uma expressão da capacidade política para negociar, intermediar e fazer alianças com aqueles que estão dentro e fora do Estado. O Congresso Nacional tem sido um lugar privilegiado para se exercer tais transações. Quando os representantes dos setores institucionais (ANDIFES, por exemplo) e acadêmico-sindicais (ANDES-SN) agem juntos no cenário nacional, eles aumentam significativamente o poder de coordenação e controle da forma institucional neste setor. Mas esse tipo de aliança depende muito do contexto da política nacional, assim como do conteúdo das medidas impostas pelo MEC para o referido setor.

Concluindo, tomando o setor federal como um todo, pode-se dizer que existe um relativo balanço ou distribuição da potência de coordenação do Estado, da academia e das instituições, ao passo que o mercado desempenha papel subordinado.

Setor Privado. A política govemamental que associa avaliação regular com recredenciamento periódico equipa o Estado com os instrumentos efetivos, que aumentam consideravelmente seu potencial de coordenação, controle e acompanhamento do desempenho do setor privado na educação superior. Assim, um médio potencial de coorde- 
nação estatal (7+) sobre o setor privado parece ser consistente com 0 discurso ideológico e a prática de um Estado democrático-liberal, que tem desenvolvido medidas concretas de liberalização e autonomização das instituições de ensino superior privado. Obviamente o Estado dispõe de grande poder de intervenção, mas a abordagem da política govemamental para a educação superior indica que o potencial de coordenação deve ser usado apenas quando as instituições fracassem em satisfazer os requisitos de qualidade. Daí a centralidade da política de avaliação. Outras formas de intervenção não são bem vistas porque poderiam entrar em conflito com o espírito geral da reforma do Estado, isto é, intervenção mínima e controle dos "produtos" em vez dos "processos". Como uma conseqüência lógica desse entendimento, as formas mercado (9+) e institucional (10+) são as duas forças mais poderosas no processo de coordenação e controle das instituições privadas. Esse equilíbrio de potencial de coordenação parece ser o resultado das relações de troca e do alto nível de commodification alcançado pelos serviços educacionais neste setor. Por outro lado, os professores das instituições privadas desempenham um papel subordinado (fraco potencial 2+) no processo de coordenação, embora sua força de trabalho seja a energia real que transforma conhecimento - ou seja, "ensino abstrato" - em serviços educacionais. Neste sentido, os incisos II e III do artigo 52 da LD (Brasil, 1996a), que contribuem para a definição da universidade brasileira, deverão ter impacto considerável na natureza e forma do potencial de coordenação/controle dos professores das instituições privadas, contrabalançando a poderosa força de coordenação institucional representada por mantenedores e suas associações. Lembremos que esses incisos não são aplicáveis às unidades não-universitárias.

A forma institucional de coordenação e controle opera efetivamente dentro de cada instituição por meio das suas estruturas administrativas e de gestão de pessoal e, em nível nacional, por meio das pressões e alianças políticas e do lobby sistemático. Ele tem um forte potencial de coordenação (10+) sobre instituições, professores e funcionários.

\section{Considerações finais}

Essas caracterizações devem ser lidas tanto a partir de uma perspectiva histórica como empírico-analítica. No sentido histórico, as forças sociais de coordenação e controle mudam quando os contextos po- 
lítico, econômico, ideológico e cultural nos quais elas agem sofrem transformações. Como conseqüência, flutuações (mudanças, alterações) no potencial de coordenação e controle é esperado que ocorram e, quando elas se materializarem, "uma demarcação móvel, sujeita à construção e desconstrução contínuas", pode ser observada. Do ponto de vista empínico-analítico, as caracterizações de instrumentos, mecanismos e do potencial de coordenação associados a cada uma daquelas forças sociais necessitam ser novamente investigadas, desenvolvidas e testadas, no sentido de verificar a eficácia explicativa a que o modelo se propõe.

Do ponto de vista teónico, o modelo de potencial de coordenação, ou da "Metáfora da Flutuação", quando comparado com o Triângulo da Coordenação de Clark, apresenta três novos elementos. Em primeiro lugar, um novo vetor de coordenação - o institucional - foi-lhe incorporado. No Brasil, a política de coordenação não pode ser completamente entendida se os múltiplos e conflitantes interesses e as demandas, característicos da forma institucional, não são incorporados. Em segundo lugar, os mecanismos e instrumentos nos quais se apóia a coordenação das atividades da educação supenior em cada forma de coordenação (o Estado, o mercado, a academia e a forma institucional) foram desenvolvidos e explorados. Eles não são, todavia, os únicos e, na verdade, o esforço investigativo deve perseguir interrogando a realidade para descobrir e/ ou propor à análise novos instrumentos, mecanismos ou facetas que contribuam para aumentar nosso entendimento acerca das relações de poder e das formas de coordenação presentes no SESB. A identificação desses mecanismos e instrumentos é relevante porque nos permite avaliar, a partir das descrições propostas, as ações potencialmente conflitantes, inconciliáveis ou cooperativas dos diversos agentes com relação a questões específicas do ensino superior. Contudo, é importante enfatizar que o poder de coordenação de qualquer uma das quatro formas descritas não depende somente dos mecanismos sugendos e de funções e objetivos que eles cumprem dentro de cada setor de ensino superior. O poder de coordenação depende, sobretudo, da competência política e técnica de agências/agentes coordenadoras/ es de gerir estrategicamente os vários mecanismos/instrumentos em determinado momento histórico. $\mathrm{O}$ terceiro aspecto a destacar vincula-se à idéia de potenciais de coordenação flutuantes, não-estáticos, simbolizados na "Metáfora da Flutuação". O modelo de potencial de coordenação é, neste sentido, não-determinista.

Recebido em janeiro de 2003 eaprovado em junho de 2003. 


\section{Notas}

1. Não se pretende, neste artigo, retomar, mesmo que de forma superficial, o debate em torno da existência ou não de um sistema nacional de educação no Brasil. O termo sistema é utilizado aqui em sentido amplo para referir-se à existência de "agências (MEC e CNE) e instituições (de ensino superior, sejam universidades ou instituições não-universitárias, públicas e privadas), postas a operar conjuntamente a partir dos marcos legais, das políticas em curso estabelecidas pelo atual grupo no poder e também em função dos interesses institucionais e dos grupos que mobilizam interesses particulares e/ ou societais tomando como referências às suas instituições" (Gomes, 2002, p. 279-280). Tal noção de sistema tomou como referência o trabalho pioneiro de Saviavi (2000).

2. Testemunha a Lei de Diretrizes e Bases da Educação Nacional em vigor desde de dezembro de 1996, a qual "derrotou" o Projeto de Lei n 1.258 de 1988 (Brasil, 1988).

3. Essa hipótese tem sido ignorada pelos estudiosos do ensino superior, que, de maneira geral, tendem a ver o Estado e o mercado como forças opostas. É necessário, pois, estudá-la sob uma perspectiva histórica, para podermos conhecer detalhadamente a formação do mercado educacional no Brasil.

4. A magnitude e importância numérica do setor privado podem ser atestadas pelas estatísticas oficiais, que demonstram que, de um total de 2.125.958 alunos matriculados no SESB no ano de 1998, 1.321.229, correspondentes a 62,1\% deles, encontram-se vinculados ao setor privado (Brasil/MEC/INEP, 1999).

5. Correspondente a 2.000 Equivalent Full Time Student Units (EFTSU) [Unidade de Equivalência ao Estudante em Tempo Integrall, na Austrália.

6. Locus de formulação, financiamento, regulação, avaliação, credenciamento, provisão de igualdades de oportunidades e de promoção de justiça social etc.

7. Goedegebuure et al. (1994) apontam a ausência, no modelo de Clark, de um ângulo institucional.

8. Professor Jacques Velloso, então membro da Câmara de Educação Superior do CNE, fez importante observação, em entrevista ao autor (realizada em 12/5/1998), a este respeito: "Então, da parte das instituições particulares, elas têm a autonomia que querem. Não há nenhuma restrição, é só você prestar as contas corretamente. Só que a autonomia de fato é da mantenedora e não da mantida, seja financeira, seja na contratação de pessoal". Esse entendimento foi particularmente expresso em parecer da Câmara de Educação Superior do CNE (Brasil/cNE, 1997c), estabelecendo que a autonomia didático-científica das universidades e dos centros universitários deve ser exercida por intermédio dos colegiados de ensino e pesquisa cujas maionias dos membros são professores. Comentando esse parecer, Jacques Velloso observa: "E a distinção fundamental nesse parecer é a de que a autonomia de gestão acadêmica tem que estar nas mãos dos professores e não da mantenedora, nas mãos da instituição, portanto, na gestão colegiada. Essa é em síntese a linha mestra do parecer".

9. Lembremos aqui que um dos três requerimentos estabelecidos pela Lei de Diretrizes e Bases da Educação Nacional, no seu artigo 52 (Brasil, 1996a), para que uma instituição de ensino superior venha a ser considerada universidade, é que ela tenha "um terço do corpo docente em regime de tempo integral". O prazo para que as atuais universidades (privadas) respondam a esse requerimento é 20 de dezembro de 2004 (LDB: artigo 88, inciso 2 das disposições transitórias). Em 1998, as universidades privadas empregavam 44.528 professores, dos quais 8.763 se encontravam em regime de tempo integral, o que significa que as universidades privadas estavam (e certamente ainda estão) muito aquém do terço determinado, que seria, segundo nossos cálculos, para o ano de 1999, em torno de 14.900 professores em regime de tempo integral (cálculos realizados a partir dos dados apresentados em Brasil/MEC/INEP, 1999). 
10. É importante notar que os interesses dos setores privados e federais não são convergentes e conservam marcadas diferenças históricas entre eles. Um bom exemplo das formas singulares de ações desses setores pode ser encontrado na fala de Eunice Durham, quando esta observa as resistências divergentes à implementação do Exame Nacional de Cursos nos idos de 1995/96. Diz ela: "Sim, todo mundo resistiu. Embora a resistência do setor público fosse mais organizada do que do setor privado. Eu reconheço que o setor privado age de forma espúnia no Brasil, no sentido que eles não se manifestam no debate público. Eles manifestam-se em termos de pressão sobre o Congresso, pressão sobre o Ministério. É uma forma diversa de resistência. O setor público é o setor no qual os professores se mobilizam. Dentro do setor privado, os professores não contam" (Eunice Durham, em entrevista ao autor, 5/5/1998).

11. Alguns depoimentos de reitores e pró-reitores de universidades federais são simpáticos à abordagem oficial desses temas, ao passo que alguns diretores de centros e chefes de departamentos consideram tais diretrizes uma evidência da astúcia centralizadora do MEC para intervir ainda mais nas atividades diárias das universidades.

\section{Referências bibliográficas}

BECHER, T.; KOGAN, M. Process and structure in higher education. London: Routledge, 1992.

BERNSTEIN, B. Pedagogy, symbolic control and identity: theory, research, critique. London: Taylor \& Francis, 1996.

BRASIL Câmara dos Deputados. Projeto de Lei n. 1.258, LDB, 1988.

BRASIL Decreto n. 2.306, de 19 agosto de 1997. Regulamenta, para o Sistema Federal de Ensino, as disposições contidas no art. 10 de Medida Provisória n. 1.477-39, de 08 de agosto de 1997, e nos artigos 16, 19, 20, 45, 46 e inciso $1^{\circ}$, 52, parágrafo único, 54 e 88 da Lei n. 9.394, de 20 de dezembro de 1996, e dá outras providências. Diário Oficial da União, Brasília, DF, 20 de agosto de 1997. Seção 1, p.17991.

BRASIL. Lei n 9.394, de 20 de dezembro de 1996. Estabelece as Diretrizes e Bases da Educação Nacional. Diário Oficial da União, Brasília, DF, 23 de dezembro de 1996a. Seção 1, p. 27839.

BRASIL Medida Provisória n. 1.972-8, de 27 de Maio de 1999. Dispõe sobre o Fundo de Financiamento ao Estudante do Ensino Superior e dá outras providências. 1999c.

BRASIL Projeto de Emenda Constitucional 370. Modifica o Artigo 207 de Constituição Federal, Diário da Câmara dosDeputados, Brasília, DF, 18 de Junho de 1996b.

BRASIL Conselho Nacional de Educação. Câmara de Educação Supenior. Parecer 600: Dispõe sobre a Autonomia das Universidades e Cen- 
tros Universitánios do Sistema Federal de Ensino, e do seu exercício pelos colegiados de ensino e pesquisa, Brasília, DF: CNE/CES, 1997.

BRASIL Ministério da Educação e do Desporto. Planejamento político-estratégico 1995-1998. Brasília, DF: MEC, 1995.

BRASIL Ministério da Educação e do Desporto. Proposta de Projeto de Lei sobre Financiamento das Universidades e demais Instituições de Ensino Superior. Brasília, DF: MEC, 1996a.

BRASIL Ministério da Educação e do Desporto. Autonomia universitária: proposta apresentada pelo MEC. Fundamentos para uma lei que regule a autonomia das universidades federais, nos termos do que estabelece a Lei de Diretrizes e Bases da Educação Nacional assim como dispõe sobre a possibilidade de ampliação da autonomia mediante contrato de desenvolvimento institucional. Brasília, DF: MEC, 1999a.

BRASIL Ministério da Educação e do Desporto. Autonomia universitária: síntese da proposta apresentada pelo MEC. Brasília, DF: MEC, 1999c.

BRASIL. Ministério da Educação e do Desporto. Projeto de Lei. Dispõe sobre a Autonomia das Universidades Federais e dá outras providências. Brasília, DF: MEC, 1999b.

BRASIL Ministénio da Educação e do Desporto. Instituto Nacional de Estudos e Pesquisas Educacionais. 'Provão 2000: exame nacional de cursos. Comissões'. Disponível em: <www.inep.gov.br/enc/provao2000/ comissoes.htm.>Acesso em: abril 2000.

BRASIL. Ministério de Educação e do Desporto. Instituto Nacional de Estudos e Pesquisas Educacionais. Sinopse estatística do ensino superior: 1998. Brasília, DF: INEP, 1999.

CLARK, B.R. The higher education system: academic organization in cross national perspective. Califomia: University of Califomia, 1983.

CLARKE, J.; NEWMAN, J. The managerial state: ower, politics and ideology in the remaking of social welfare. London: Sage, 1997.

FOUCAULT, M. The subject and the power. In: NASH, K. (Ed.). Reading in contemporary political sociology. Oxford: Blackwell, 2000

GOEDEGEBUURE, L et al. Higher education policy: an intemational comparative perspective. Oxford: Pergamon, 1994. 
GOMES, A.M. The Cardoso government's project for higher education: procrustean solutions in the management of change? 2000a. - Tese (Doutorado em Educação) - Graduate School of Education, University of Bristol, Bristol.

GOMES, A.M. Higher education autonomy policy in Brazil: changing the relationship between the State and higher education. Higher Education Review, England, v. 32, n. 2, 2000b.

GOMES, A.M. De-democratising higher education and de-construction of the University vocation. Texto apresentado na Conferência Intemacional Cosmopolis: democratising global economy and culture, 2-4 Jun. 2000c, Helsinki, Finlândia.

GOMES, A.M. O exame nacional de cursos como política de avaliação do ensino superior: origens, contrastes e sua importância na política estatal de regulação do ensino superior. In: REUNIẪO ANUAL DA ANPED, 24., 2001, Caxambu. Anais... Caxambu: ANPED, 2001. 1 CD-ROM

GOMES, A.M. Política de avaliação da educação superior. Educação \& Sociedade, Campinas, v. 23, n. 80, set. 2002.

HABERMAS, J. The public sphere. In: NASH, K. (Ed.). Reading in contemporary political sociology. Oxford: Blackwell, 2000.

HAYEK, F.A. The road to serfdom. London: Routledge, 1997.

MARGNSON, S. Competition and contestability in Australia higher education, 1987-1997. Australia Universities' Review, Australia, v. 40, n. 1, p. 5-14, 1997.

MILLER, $H$. The management of change in universities: universities, state and economy in Australia, Canada and the United Kingdom. Buckingham: SRHE; Open University, 1995.

NEAVE, G. On being economical with university autonomy: being an account of the retrospective joys of a whiten constitution. In: Tight, M. (Ed.). Academic freedom and responsibility. Milton Keynes: SRHE; Open University, 1988.

SAVIANI, D. Educação brasileira: estrutura e sistema. Campinas: Autores Associados, 2000.

SILVA, J.A.A. Auto-defesa do ministro da Educação. Jornal da Ciência, Rio de Janeiro, v. 14, n. 431, 2000. 
STEINMETZ, G. Introduction: culture and the State. In: STeINMETZ, G. (Ed.). State/culture: state-formation after the cultural turn. Ithaca: Comell University, 1999.

TAYLOR, D.D. Changing policy in Australian higher education. In: NEAVE, G.; VAN VUGHT, F.A. Prometheus bound: the changing relationship between govemment and higher education in Westem Europe. Oxford: Pergamon, 1991. p. 185-214.

WILLAMS, G. The market route to mass higher education: British experience 1979-1996. Higher Education Policy, London, v. 10, n. 3/4, p. 275-289, 1997. 